\title{
Utilization-focused scientific policy advice: a six-point checklist
}

\section{Journal Article}

Author(s):

Sager, Fritz; Mavrot, Céline; Hinterleitner, Markus; Kaufmann, David (D; Grosjean, Martin; Stocker, Thomas F.

Publication date:

2020

Permanent link:

https://doi.org/10.3929/ethz-b-000416730

Rights / license:

In Copyright - Non-Commercial Use Permitted

Originally published in:

Climate Policy 20(10), https://doi.org/10.1080/14693062.2020.1757399 


\section{A Six-Point Checklist for Utilization-focused Scientific Policy Advice}

Fritz Sager, Prof. Dr., University of Bern, KPM Center for Public Management, currently Center for European Studies at Harvard University and Harvard Kennedy School Ash Center for Democratic Governance and Innovation, contact: fritz.sager@kpm.unibe.ch

Céline Mavrot, PhD, University of Bern, KPM Center for Public Management, contact: celine.mavrot@kpm.unibe.ch

Markus Hinterleitner, PhD, Brown University, contact: markus_hinterleitner@brown.edu

David Kaufmann, Prof. Dr., ETH Zurich, contact: kadavid@ethz.ch

Martin Grosjean, Prof. Dr., University of Bern, Oeschger Centre for Climate Change Research, contact: martin.grosjean@oeschger.unibe.ch

Thomas F. Stocker, Prof. Dr., University of Bern, Physics Institute, Climate and Environmental Physics and Oeschger Centre for Climate Change Research, contact: stocker@climate.unibe.ch

Article published in Climate Policy, https://doi.org/10.1080/14693062.2020.1757399 


\section{Abstract}

Knowledge utilization depends on how well the scientific community communicates knowledge to its target audiences' needs. We argue that policy-relevant science communication can increase the real-life impact of scientific evidence by moving beyond political agendasetting and providing concrete advice to policy drafters. Agenda-setting seeks to raise politicians' and the wider public's awareness of a problem (problem advice). However, for scientific evidence to translate into effective policy interventions, the scientific community and non-governmental organizations (NGOs) must also provide policy drafters with advice on policy design and implementation (policy advice). Political attention is volatile, and - except for particularly policy-driven and solution-focused actors - politicians have little incentive to address long-term issues such as climate change if voters do not punish short-term thinking. In contrast, the public administration (government agencies) carries out long-term expert work. Government agencies are therefore the primary recipients of evidence-based knowledge transfer that aims to create concrete policy solutions. We develop hands-on recommendations for tailoring scientific advice to the needs of policy drafters through a six-point checklist. Based on utilization-focused evaluation research, we argue that scientific evidence should not only address the causes of public problems but also the effectiveness of proposed policy solutions and the consequences of policy decisions. We also highlight the need to assess the political feasibility of a given policy proposal (potential oppositions and stumbling blocks) and its practical implementability (likely reaction of the target groups). Ensuring effective policy advice requires transdisciplinary dialogue between natural, social, and policy scientists, as well as dialogue between research and government agencies. 
Key Policy Insights

- There is a gap between public and political awareness of climate change issues and effective policy solutions.

- Due to their respective roles within the policy process, politicians and government agencies have different knowledge needs.

- In addition to providing politicians and the general public with problem advice, a specific form of policy advice, that is, policy-prescriptive evidence-based information, should be developed and provided for policy drafters within government agencies.

- Natural, social and policy scientists must team up to provide policy advice that is not only evidence-based but also utilization- focused.

Keywords

Policy advice, science communication, interdisciplinary dialogue, knowledge utilization, government agencies, policy design 


\section{Introduction}

The recent reactions of politicians and the wider public to the "Fridays for Future" 1 demonstrations suggest that the problem awareness of human made climate change is probably larger now than ever before. To ensure that this awareness will not dissipate without creating a lasting impact, modern democracies need to devise effective policy solutions. In the following, we argue that scientific advice that goes beyond general science communication can help this become a reality.

Discussions about how to close the evidence-action gap on climate change frequently revolve around the scientific community's own role and actions. How should scientists communicate climate change to the wider public (Gupta, 2011), and what is effective text (Stocker \& Plattner, 2016) and imagery (Harold et al., 2016)? How should scientists confront climate science denialism (Hansson, 2018)? How should scientists inform international negotiations and guide political choices (Ourbak \& Tubiana, 2017)? These important questions indicate that it is crucial for the scientific community and science-oriented NGOs to reflect on how their information activities can help to devise effective policy solutions.

In his seminal book on 'Utilization-focused evaluation', Michael Quinn Patton (2008) makes the simple argument that knowledge utilization depends on the form of knowledge communication. We posit that diversifying the scientific community's communication strategy, both in terms of targets and content can spur the translation of scientific evidence into policy. We make the case for actively directing policy advice to policy drafters as a distinct form of knowledge transfer that is at the interface of science and politics. While numerous scientists provide advice to government agencies around the world, we are unaware of scholarly

\footnotetext{
1 Fridays for Future is a youth social movement launched in Sweden in 2018 by the then 15 -year-old Greta Thunberg to urge authorities to address the climate crisis. The movement has since resonated internationally through climate strikes and demonstrations. Source: https://www.fridaysforfuture.org/about. See also Hagedorn et al. (2019).
} 
endeavours that systematize this practice, specify the conditions for its success, or provide a comprehensive list of steps that policy advice must take in order to make an impact. To fill this gap in the literature, we propose a list of six core points that policy advice should include in order to support the development of effective policy solutions.

The climate research community has long been seeking ways to address the growing gap between available scientific evidence and actual policies (Meckling et al., 2015; Kennel et al., 2016).

Some authors have argued that only a refined understanding of collective decision-making processes can pave the way for encompassing and sustainable policy solutions to climate change (Biesbroek et al., 2015). These authors argue that it is crucial to acknowledge that the political system does not automatically react to social needs in a functionalist manner and that policymaking is a complex multi-actor process. Indeed, the broader challenge of communication between research and practice has been analyzed from a number of perspectives. For example, the Cassandra effect holds that repeated messaging wears off (Redford \& Sanjayan 2003), the implementation gap problem claims that policy decisions do not necessarily lead to action (Hill \& Hupe 2014), and the analysis paralysis phenomenon suggests that more research findings obfuscate appropriate policy solutions (Francis 2016). Our proposal builds on this research by distinguishing between two targets of scientific communication: politicians and the general public on the one hand, and policy drafters (i.e., government agencies) on the other hand. We posit that while the former need policy-relevant scientific information, the latter can be provided with policy-prescriptive information that can be directly converted into policy solutions. We suggest that this second type of advice deserves more systematic attention from the climate research community.

In the following, we apply our argument to the case of climate research. We first distinguish between the roles of, on the one hand, politicians and, on the other, policy drafters that work in 
government agencies who are part of the policy process, and we specify their knowledge needs. We then argue that these two actors require two forms of scientific advice: problem advice, commonly referred to as science communication, for politicians; and policy advice, for government agencies. Problem advice is important for creating problem awareness and pressure for policy change. However, only policy advice includes recommendations on policy design and implementation that are required for effective policy interventions. We then provide a concrete proposal on how policy advice should be designed in order to be relevant to policy drafters.

\section{Public Policy as a Process}

Translating scientific evidence into concrete policy recommendations is a challenging task. Whereas the scientific evidence of human made climate change is robust and clear in the scientific community (IPCC, 2013), it has proven very difficult and slow to translate this knowledge into binding and effective policy interventions. The first scientific assessment on global climate change dates back to 1979 (Charney et al., 1979), and the Intergovernmental Panel on Climate Change (IPCC) conducted its first formal assessment in 1990 (IPCC, 1990). However, the Paris Agreement, with which countries committed to contributing to the mitigation of climate change, only came into being in 2015 . The nationally determined contributions to greenhouse gas emission reductions (NDCs) that countries make to achieve the global goals set forth in the Paris Agreement rest on policy commitments that need to be translated into effective public policies at the national level (Viñuales et al. 2017).

We employ the analytical heuristic of the policy cycle to conceptualize this translation process. Modern policy studies consider public policy as a social and political process rather than a static regulation. The notion of the policy cycle is a stage heuristic that conceptualizes the policy process as overlapping but distinct phases that each include specific sets of actors and decisions (Wegrich \& Jann, 2006). As a heuristic, the policy cycle is not an empirical description of 
reality but rather a stylized account of the policy process that allows for a better understanding of the various steps needed to translate political intentions into public policy.

In the agenda-setting phase, agenda-setters convince the wider public of the existence of a problem. Once a problem is on the political agenda, societal actors, experts, and politicians develop and deliberate on policy solutions in the formulation phase. The political body that is formally responsible selects one of these proposals in the decision phase. However, a policy is not finished once it is designed on paper and decided upon. It also needs to be implemented. In the subsequent implementation phase, government agencies implement the chosen policy proposal. The public and politicians then assess the effects of the policy in the evaluation phase. A policy may fail due to the selection of a wrong policy proposal, poor implementation, or resistance by lobbying organizations and pressure groups. Policy design and policy implementation are therefore two necessary conditions for a successful policy intervention.

The stage heuristic of the policy process demonstrates that both problem advice and policy advice are essential for translating scientific evidence into effective policies. While problem advice is crucial in the agenda-setting phase in order to create problem awareness, policy advice is crucial in the formulation, decision, and implementation phases in order to develop and implement effective policy solutions.

\section{Two Forms of Scientific Advice Aimed at Politicians and Government Agencies}

Two basic actor categories are needed to translate international environmental treaties like the Paris Agreement into effective policy action at the (sub-)national level: politicians and policy drafters, i.e. the experts in government agencies (Page and Jenkins 2005). In the following, we systematically distinguish between the two forms of scientific advice that the climate research community and science-oriented NGOs can provide to these actor groups (see Table 1 for an overview). 
Table 1: Two Forms of Scientific Advice

\begin{tabular}{l|l|l} 
& Problem Advice & Policy Advice \\
\hline Primary Targets & Politicians and the public & Policy drafters in government \\
& & agencies \\
\hline Focus & Problem & Solution \\
\hline Ontology & Descriptive/normative & Causal/analytical \\
\hline Goal & Problem awareness & Policy solution \\
\hline Time frame & Short- to medium-term & Medium- to long-term \\
\hline Role in Policy Process & Agenda setting & Policy design and \\
& & implementation
\end{tabular}

Problem advice addresses the (interested) public, politicians, opinion makers, and the media in order to raise awareness of a problem. Problem advice is mainly descriptive: it states that a problem needs to be solved and proposes general solutions, or scenarios, rather than elaborating on concrete policy proposals. Problem advice is supposed to create bottom-up societal pressure that feeds into the political system, prompting politicians to address the problem. The vehicles for creating bottom-up pressure include elections, mainstream media, online media, social media, scientific events, and political manifestations. These public awareness-raising efforts are crucial for laying the groundwork for future change. However, due to national electoral terms, politicians often have little incentive to address long-term problems (Jacobs, 2011). As previously mentioned, problem advice focuses on the policy agenda-setting phase (Tesar et al., 
2016) but overlooks other crucial phases of the policy cycle, especially the policy implementation phase.

Policy advice, on the other hand, primarily targets government agencies. Government agencies generally have the task of putting political will into practice. 2 To tackle this role, policy drafters possess a primarily scientific or vocational training that is relevant to the policy field that agencies are active in. Government agencies are therefore science-prone organizations. Moreover, they are not subject to voter volatility to the same degree as elected executives. In fact, research on shadow networks (Olsson et al., 2006) or super wicked problems (Levin et al., 2012) has demonstrated the crucial role of government agencies in tackling ecological problems. Acting on behalf of their political superiors, they have the important task of codesigning report outlines, which gives them the power to address relevant questions and to select the information they use. In order to succeed, they need a set of evidence-based policy proposals that have a chance of being implemented in today's complex decision-making processes (Wegrich \& Jann, 2006). The likelihood of finding individuals who base their decisions on scientific evidence is higher among public agents in environmental agencies than among politicians because of their different roles, missions, and constraints (that is, long-term vs. short-term horizon, low profile activity vs. political salience, expert vs. elective legitimacy, specialized vs. generalist profile) (Pollitt, 2008).

Policy advice thus differs from problem advice by explicitly addressing policy drafters, informing them of the causal relationships between a problem (in this case, human made climate change), causal contributors to the problem causers (e.g., $\mathrm{CO}_{2}$ emitters), and possible policy interventions (e.g., $\mathrm{CO}_{2}$ taxes). Since a well-designed policy may still fail if it is not properly implemented (O'Toole, 2000), policy advice also provides concrete implementation advice.

2 The policy drafters who work for these agencies are not identical to implementing agents. However, they take practical experience into account to prevent implementation problems (e.g. Treves et al., 2009). 
Policy advice is in line with the assumption that policy interventions that directly focus on particular target groups can correct problems. Target groups are the causal contributors to the problem the policy aims to solve. Consequently, policy advice works with two hypotheses: first, that the target group causally contributes to the problem, and second, that the selected policy interventions will change the target group's behaviour so that it no longer causes the problem. Problem advice regarding climate change is well-established and the scientific community has generally developed a deep understanding of the matter. In the authors' experience, funding agencies and universities consider this form of advice as the gold standard of communication and invest a lot of energy in it (see also Aines \& Aines, 2019; Gupta, 2011; Holt, 2018). The prominence of problem advice does not mean that climate scientists do not work with relevant government agencies. While it is not unusual for research institutes to establish ties with governments and to act as policy advisors, the question of how to draft effective policy advice would deserve a more in depth discussion within the scientific community in order to structure and systematize this practice. The relative overshadowing of policy advice is reinforced by the fact that, by its very nature, problem advice is supposed to be highly salient whereas policy advice takes place in confidential spheres. Moreover, policy advice is mostly a nation-specific activity, which impedes international scientific exchange on this matter.

Some interesting propositions related to policy advice have already been discussed, such as the need to submit governments to increased accountability standards on the use of evidence in their policy decisions (Artelle et al., 2014; Carroll et al., 2017), to strengthen collaborations between scholars and practitioners around the concrete applications of scientific knowledge in environmental programmes (Byerly et al., 2018), or to create better interfaces between scientists, policymakers, and policy stakeholders (Sullivan et al., 2006), even in the evaluation phase of the policy (Norris, 2004). For our part, we focus on how researchers can organize scientific knowledge in order to make it consistent with actual policy needs. We suggest that 
policy evaluation research provides an ideal basis for this task. Policy evaluation has longstanding experience adapting knowledge communication in order to maximize the chances of knowledge utilization (Vedung, 2009; Weiss, 1999). In the next section, we propose a form of policy advice that draws on utilization-focused evaluation (Patton, 2008) and that specifically targets government agencies.

\section{Drafting Effective Policy Advice}

Research on evidence-based policy and knowledge utilization corroborates the hypothesis that the public administration is the main user of scientific evidence for policy-making. Evidencebased policy research shows that evidence always "enters into an existing soup of values, beliefs, preferences, and needs" (Henry 2000: 8; see also Kinzig et al. 2013). In this process, interventions are often chosen on the basis of implicit judgments about feasibility that are prone to subjective bias and personal opinion rather than careful scrutiny of possible interventions (Van Eeden et al. 2018). Thus, expert policy-making is far from neutral, and it also serves a political function of self-legitimization by using science and the claim of independence, of high internal reliability, and of result-based outcomes (Sager \& Mavrot, forthcoming).

When employing scientific advice, policy drafters put it to the so-called truth test and utility test in order to assess its usefulness in practice (Weiss \& Bucuvalas, 1980). Both tests acknowledge that the worldviews of public agents bias them into making snap judgments about what is true and what is applicable, often in defiance of rigorous scientific evidence. The truth test considers empirically established causality, and the utility test considers the practical plausibility of the given recommendations. Both tests follow the perception of the agents who are to use scientific advice. In order to pass both tests, scientific advice must be based on strong inference and be applicable. 
The truth test is at the heart of multi-stage scientific assessments carried out by expert bodies such as the IPCC. However, while the IPCC's assessment of the evidence provides the scientific basis for informed policy decisions, direct policy advice is purposefully excluded from the scope of its mission (see Art. 2 of the Principles Governing IPCC Work). Policy advice requires a combination of truth and utility tests. To meet these requirements, policy advice need not only draw on scientific knowledge about the causes of climate change, but also on relevant policy insights (Nicholson et al., 2012) or even on advocacy techniques (Cockrell et al., 2018). In the following, we propose a six-point checklist for developing policy advice that passes both the truth test and the utility test:

1. State the problem to be solved by the policy and corroborate it with reliable, replicable, accurate, and precise observations. For example, there is reliable and robust evidence that there is a problem of environmental shifts caused by climate change.

2. Define the part of the problem that can be addressed with policy and justify its priority.

3. State the causes of the problem and identify the causal contributors to the problem as (a) policy target group(s). Provide empirical evidence for the causes of the problem. Researchers should state if there are areas where action needs to be taken but where causality is difficult or impossible to establish, or where contradictory evidence exists.

4. Identify policy proposals that may change the target groups' behaviour so that they will no longer cause the problem. If possible, provide evidence of the intervention's effectiveness.

5. Assess the feasibility of the policy proposal: How strong are the political opponents? Do they have access to decision making? Does the proposal break with established policy or does it fit with it? How can the political salience of the proposal be reduced in case of polarization? Can the policy proposal be framed as a win-win solution (in the short and/or long term) in order to increase its political acceptance? What are the 
potential stumbling blocks from a more structural perspective? How can policy proposals that require infrastructural or system changes be put into practice?

6. Assess the implementability of the policy proposal: How likely is the target groups' compliance or resistance? How strong will the reaction be? How likely is the implementing bodies' compliance or resistance? Implementing agencies sometimes resist interventions that are potentially effective because of ideology, perceived negative consequences, the personal preferences of leaders, tradition, lack of resources, or the lack of skills (Hill \& Hupe, 2014). How can resistances be addressed and mitigated? What resources and authoritative allies does the policy need to guarantee successful implementation?

Developing policy advice according to this checklist requires co-production between natural scientists, social scientists, and policy scientists. While natural scientists are well-equipped to contribute to points 1-3, social scientists, and policy scientists have expertise that informs points 4-6. The checklist thus recommends a dialogue across disciplinary boundaries when advising government agencies. Moreover, scientists and government agencies must develop a discussion culture and establish effective communication channels and platforms that allow for both evidence-based and utilization-focused policy advice. National governments should acknowledge the policy advice role of the climate research community and provide it with a clear mandate for this task. Policy advice could either be provided by scientists on an ad hoc basis, for instance, in the framework of policy evaluation activities, or by national or international bodies that would be specifically established for this purpose. While the IPCC already addresses the three first points of the proposed checklist, the last three have yet to be covered through proper policy advice.

\section{Conclusions}


A number of conditions must be met in order for utilization-focused policy advice to become a reality on a wider scale. First, the climate research community must specifically acknowledge that government agencies are direct and important targets of scientific advice that require a specific form of policy-prescriptive evidence-based information. Second, natural scientists, social scientists, and policy scientists must engage in a dialogue to provide the full spectrum of advice that can be derived from their research on human made climate change. Third, and most importantly, the checklist indicates that scientific advice must go beyond providing scientific evidence. Evidence alone is not enough for policy-makers to take appropriate measures because it only passes their truth test but not their utility test. Therefore, to become politically relevant, advice has to address very practical concerns.

The form of policy advice that we propose in this paper makes statements about the causality between the problem to be solved and the contributors to the problem (the policy's target group). Moreover, the proposed form of policy advice addresses the causality between the policy intervention and the target group behaviour. While scientists are well equipped to identify the first causality, social scientists and policy scientists can establish the second causal link. The response of the target group can be very strong and negative at times, as the 'Gilets jaunes' movement's violent protests against higher gas prices in France demonstrate. Policy advice thus needs to consider the possibility of resistance as well as compliance to the proposed policy. Resistance may not only stem from the target group but also from implementing agents who disagree with the policy. Overall, the proposed form of policy advice acknowledges that policy is not a purely technocratic endeavour but a political one, helping scientists factor in human and political aspects.

When scientific findings are politically relevant, as is the case in climate research, scientists assume a political role when informing policy-makers. However, giving policy advice does not mean that scientists become politicized or activists. Evidence-based policy emphasizes 
scientists' understanding of how policy differs from research findings and their awareness of this fact when they inform policy-makers. We hope that this checklist helps to develop impactful policy advice. 


\section{References}

Aines, R. D., \& Aines, A. L. (2019). Championing Science. Oakland, CA: University of California Press.

Artelle, K.A., Reynolds, J.C., Paquet, P.C., Darimont, C.T. (2014). When Science-Based Management Isn't. Science, 343, 1311. doi: 10.1126/science.343.6177.1311-a

Biesbroek, R., Dupuis, J., Jordan, A., Wellstead, A., Howlett, M., Cairney, P., ...Davidson, D. (2015). Opening up the black box of adaptation decision-making. Nature Clim. Change, 5, 493494. doi.org/10.1038/nclimate2615

Byerly, H., Balmford, A., Ferraro, P.J., Wagner, C.H., Palchak, E., Polasky, S., ...Fisher, B., (2018). Nudging pro-environmental behavior: evidence and opportunities. Front. Ecol. Environ., 16, 159-168. doi:10.1002/fee.1777

Carroll, C., Hartl, B., Goldman, G.T., Rohlf, D.J., Treves, A., Kerr, J.T., ...Watson, J.E.M. (2017). Defending scientific integrity in conservation policy processes. Conservation Biology, 31, 967-975. doi: 10.1111/cobi.12958

Charney, J.G., A. Arakawa, D.J. Baker, B. Bolin, R.E. Dickinson, R.M. Goody, C.E. Leith, H.M. Stommel, and C.I. Wunsch, Carbon Dioxide and Climate: A Scientific Assessment, 22 pp., National Academy of Science, Washington, DC, 1979.

Cockrell, M., Dubickas, K., Hepner, M., Ilich, A., McCarthy, M. (2018). Embracing Advocacy in Science. Fisheries, 43, 179-182. doi: 10.1002/fsh.10055.

Michael Francis (2016) Perspectives from the Field: Opinion: The NEPA and Major Water Resource Planning for the Future. What's the problem? Analysis Paralysis, Environmental Practice, 18, 69-71, DOI: 10.1017/S1466046615000423 
Gupta, J. (2011). Communicating climate change to the wider public. Clim. Policy, 11, 834835. doi.org/10.3763/cpol.2009.0686

Hagedorn, G., et al. (2019). The concerns of the young protesters are justified A statement by Scientists for Future concerning the protests for more climate protection. Gaia-Ecological Perspectives for Science and Society, 28(2), 79-87. doi.org/10.14512/gaia.28.2.3

Hansson, S. O. (2018). Dealing with climate science denialism: experiences from confrontations with other forms of pseudoscience. Clim. Policy, 18, 1094-1102. doi.org/10.1080/14693062.2017.1415197

Harold, J., Lorenzoni, I., Shipley, T. F., \& Coventry, K. R. (2016). Cognitive and psychological science insights to improve climate change data visualization. Nature Clim. Change, 6, 10801089. doi.org/10.1038/nclimate3162

Henry, Gary T. (2000). Using Evaluation Findings for Policy: A Realist Perspective. Paper presented at the 2000 European Evaluation Society Conference.

Holt, R. (2018). A tale of two cultures. Science, 359, 371. doi.org/10.1126/science.aat0588

Hill, M. and P. L. Hupe . (2014). Implementing Public Policy: An Introduction to the Study of Operational Governance (3rd edn). London: Sage.

IPCC (1990). Climate Change: The IPCC Scientific Assessment [Houghton, J. T., Jenkins, G. J., Ephraums, J. J. (eds.)], Cambridge, New York, Melbourne: Cambridge University Press, 365 pp.

IPCC (2013). Climate Change 2013: The Physical Science Basis. Working Group I Contribution to the Fifth Assessment Report of the Intergovernmental Panel on Climate Change [Stocker, T. F., et al. (eds.)], Cambridge, New York: Cambridge University Press, 1535 pp. 
Jacobs, A. M. (2011). Governing for the Long Term: Democracy and the Politics of Investment. Cambridge: Cambridge University Press.

Kennel, C. F., Briggs, S., \& Victor, D. G. (2016). Making climate science more relevant. Science, 354, 421-422. doi.org/10.1126/science.aag3248

Kinzig, A.P., Ehrlich, P.R., Alston, L.J., Arrow, K., Barrett, S., Buchman, T.G., ... Saari, D., (2013). Social Norms and Global Environmental Challenges: The Complex Interaction of Behaviors, Values, and Policy. Bioscience, 63, 164-175.

Levin, K., Cashore, B., Bernstein, S., \& Auld, G. (2012). Overcoming the tragedy of super wicked problems: constraining our future selves to ameliorate global climate change. Policy Sci, 45, 123-152. doi.org/10.1007/s11077-012-9151-0

Meckling, J., Kelsey, N., Bider, E., \& Zysman, J. (2015). Winning coalitions for climate policy. Science, 349, 1170-1171. doi.org/10.1126/science.aab1336

Nicholson, E., Collen, B., Barausse, A., Blanchard, J. L., Costelloe, B. T., Sullivan, K. M. E., ...Milner-Gulland E. J. (2012). Making robust policy decisions using global biodiversity indicators. PLoS ONE, 7, e41128. doi.org/10.1371/journal.pone.0041128

Norris, S., (2004). Only 30: A portrait of the Endangered Species Act as a young law. Bioscience, 54, 288-294. doi.org/10.1641/0006-3568(2004)054[0288:OAPOTE]2.0.CO;2

Olsson, P., Gunderson, L. H., Carpenter, S. R., Ryan, P., Lebel, L., Folke, C., \& Holling, C. S. (2006). Shooting the rapids: navigation transitions to adaptive governance of social-ecological systems. Ecology and Society, 11, 18.

O'Toole, L. J. Jr. (2000). Research on policy implementation: assessment and prospects. $J$. Public Adm. Res. Theory, 10, 263-288. doi.org/10.1093/oxfordjournals.jpart.a024270 
Ourbak, T., \& Tubiana, L. (2017). Changing the game: the Paris Agreement and the role of scientific communities. Clim. Policy, 17, 819-824. doi.org/10.1080/14693062.2017.1348331

Principles Governing IPCC Work (last updated October 2013), https://www.ipcc.ch/site/ assets/uploads/2018/09/ipcc-principles.pdf

Page, Edward C., and Bill Jenkins (2005). Policy Bureaucracy: Government with a Cast of Thousands. New York, NY/Oxford, UK: Oxford University Press.

Patton, M. Q. (2008). Utilization-Focused Evaluation. Thousand Oaks, CA: Sage.

Pollitt, C. (2008). Time, Policy, Management: Governing with the Past. Oxford, New York: Oxford University Press.

Redford, K.H., Sanjayan, M.A., (2003). Retiring Cassandra. Conservation Biology, 17, 14731474.

Sager, F. \& Mavrot, C. (forthcoming). „Participatory vs Expert Evaluation Styles”, in: Michael Howlett, M. \& Tosun, J. (eds.). Routledge Handbook of Policy Styles. London / New York: Routledge.

Stocker, T. F., \& Plattner, G.-K. (2016). Making use of the IPCC's powerful communication tool. Nature Clim. Change, 6, 637-638. doi.org/10.1038/nclimate3010

Sullivan, P.J., Acheson, J.M., Angermeier, P.L., Faast, T., Flemma, J., Jones, ...Zanetell, B.A., (2006). Defining and implementing best available science for fisheries and environmental science, policy, and management. Marine Sciences Faculty Scholarship, 31, 460-465.

Tesar, C., Dubois, M.-A., \& Shestakov, A. (2016). Toward strategic, coherent, policy-relevant arctic science. Science, 353, 1368-1370. doi.org/10.1126/science.aai8198 
Treves, A., Wallace, R.B., White, S. (2009). Participatory planning of interventions to mitigate human-wildlife conflicts. Conservation Biology, 23, 1577-1587. doi: 10.1111/j.15231739.2009.01242.x

van Eeden, L.M., Eklund, A., Miller, J.R.B., López-Bao, J.V., Chapron, G., Cejtin, M.R., et al. (2018). Carnivore conservation needs evidence-based livestock protection. PLoS Biol, 16,: e2005577. https://doi.org/10.1371/journal.pbio.2005577 (9)

Vedung, E. (2009). Public Policy and Program Evaluation (4th ed.). New Brunswick, London: Transaction Publishers.

Viñuales J. E., Depledge, J., Reiner D. M. \& Lees, E. (2017). Climate policy after the Paris 2015 climate conference, Climate Policy, 17(1): 1-8.

Wegrich, K., \& Jann W. (2006). Theories of the Policy Cycle. In F. Fischer, G. J. Miller, \& M. S. Sidney (Eds.), Handbook of public policy analysis (pp. 43-62). New York: Routledge.

Weiss, C. H. (1999). The interface between evaluation and public policy. Evaluation, 5, 468486.

Weiss, C. H., \& Bucuvalas, M. J. (1980). Truth tests and utility tests: decision-maker's frames of reference for social science research. Am. Sociol. Rev., 45, 302-313. doi.org/10.2307/2095127

Williams, K. (2019). Credibility in Policy Expertise: The Function of Boundaries Between Research and Policy. Policy Stud J. doi.org/10.1111/psj.12342 